\title{
Análise do líquido cefalorraquidiano de bugio-ruivo (Alouatta guariba) ${ }^{1}$
}

\author{
Marcos V. Tranquilim²*, Guilherme S. Cardoso ${ }^{3}$, Marta C.T. Heckler ${ }^{2}$, Carlos R. Teixeira ${ }^{4}$, \\ Raimundo S. Lopes ${ }^{5}$, Regina K. Takahira ${ }^{5}$, Luiz A.L. Resende ${ }^{6}$ e Rogério M. Amorim ${ }^{5}$
}

\begin{abstract}
Tranquilim M.V., Cardoso G.S., Heckler M.C.T., Teixeira C.R., Lopes R.S., Takahira R.K., Resende L.A.L. \& Amorim R.M. 2013. [Cerebrospinal fluid analysis of the howler monkey (Alouatta guariba).] Análise do líquido cefalorraquidiano de bugio-ruivo (Alouatta guariba). Pesquisa Veterinária Brasileira 33(12):1466-1470. Departamento de Clínica Veterinária, Faculdade de Medicina Veterinária e Zootecnia, Universidade Estadual Paulista, Campus de Botucatu, Distrito de Rubião Júnior, Botucatu, SP 18618-000, Brazil. E-mail: rmamorim@fmvz.unesp.br

This survey was conducted with the objective of developing and adapting diagnostic techniques in neurology for non-human primates, of the species Alouatta guariba Geoffroy Saint-Hilaire, 1812 (howler monkey) healthy and kept in captivity. Physical-chemical analyses were carried out in cerebrospinal fluid and its pressure measurement in the cisterna magna. Eight animals were used for the analysis of cerebrospinal fluid. In all procedures, were used chemical restraint and anesthesia with ketamine, xylazine and association of midazolam and inhalational anesthesia with isoflurane for carrying out the spinal tap. The cerebrospinal fluid analysis showed average values: protein: 16.92 \pm 9.84 ; glucose: $131.25 \mathrm{mg} / \mathrm{dL} \pm 106.7$; $\mathrm{pH}$ : $8.37 \pm 0.69$; nucleated cells: $0.5 / \mathrm{mm}^{3} \pm 0.75$; red blood cells: $49.37 / \mathrm{mm}^{3} \pm 111.76$ and CSF cisternal pressure: $7.37 \mathrm{~cm} \mathrm{H} 20 \pm 1.77$. This study demonstrated the safety and efficacy of cerebrospinal fluid collection in the cisterna magna of Alouatta guariba, and the reference values for the specie.
\end{abstract}

INDEX TERMS: Alouatta guariba, howler monkey, cerebrospinal fluid.

RESUMO.- A presente pesquisa foi realizada com o objetivo de desenvolver e adaptar técnicas diagnósticas em neurologia para primatas não humanos, da espécie Alouatta guariba Geoffroy Saint-Hilaire, 1812 (bugio-ruivo) saudáveis e mantidos em cativeiro. Foram realizadas análises físico-químicas e citológicas do líquido cefalorraquidiano obtido

\footnotetext{
${ }^{1}$ Recebido em 22 de setembro de 2013.

Aceito para publicação 20 de novembro de 2013.

${ }^{2}$ Pós-Graduando do Departamento de Clínica Veterinária, Faculdade de Medicina Veterinária e Zootecnia (FMVZ), Universidade Estadual Paulista "Júlio de Mesquita Filho" (Unesp), Campus de Botucatu, Distrito de Rubião Júnior s/n, Botucatu, SP 18618-000, Brasil. E-mail: tranquiveter@hotmail.com

${ }^{3}$ Pós-Graduando do Departamento de Cirurgia e Anestesiologia Veterinária, FMVZ-Unesp, Botucatu, SP.

${ }^{4}$ Docente do Departamento de Cirurgia e Anestesiologia Veterinária, FMVZ-Unesp, Botucatu, SP.

${ }^{5}$ Docente do Departamento de Clínica Veterinária, Serviço de Neurologia Veterinária, FMVZ-Unesp, Botucatu, SP. *Autor para correspondência: rmamorim@fmvz.unesp.br

${ }^{6}$ Docente do Departamento de Neurologia, Psiquiatria e Psicologia Médica, Faculdade de Medicina de Botucatu, Unesp, Botucatu, SP.
}

na cisterna magna de oito bugios-ruivos. Para realização dos exames, todos os animais foram contidos quimicamente com associação de cetamina, xilazina e midazolam e anestesia inalatória com isoflurano. Os resultados das análises do líquido cefalorraquidiano demonstraram valores médios de proteína: $16,92 \mathrm{mg} / \mathrm{dL} \pm 9,84$; glicose: $131,25 \mathrm{mg} / \mathrm{dL} \pm 106,7$; pH: $8,37 \pm 0,69$; células nucleadas: $0,5 / \mathrm{mm}^{3} \pm 0,75$; hemácias: $49,37 / \mathrm{mm}^{3} \pm 111,76$ e pressão: $7,37 \mathrm{~cm} \mathrm{H}_{2} \mathrm{O} \pm 1,77$. 0 trabalho demonstrou a segurança e a eficácia da colheita do líquido cefalorraquidiano na cisterna magna de Alouatta guariba e os valores de referência para a espécie.

TERMOS DE INDEXAÇÃO: Alouatta guariba, bugio-ruivo, líquido cefalorraquidiano.

\section{INTRODUÇÃO}

Os animais do gênero Alouatta, popularmente chamados de bugios ou macacos gritadores ou roncadores, apresentam ampla distribuição geográfica na região neotropical, ocorrendo desde o México até o estado do Rio Grande do Sul, no 
Brasil (Gregorin 2006). Trata-se de animais adaptados ao meio ambiente onde vivem, e que apresentam inúmeras diferenças fisiológicas, anatômicas e comportamentais de outros gêneros de primatas. 0 estudo da biologia e da medicina desses indivíduos, que já se encontram em cativeiro, é de grande importância para um melhor entendimento da espécie, das enfermidades mais comuns e consequentemente, o desenvolvimento de ações conservacionistas. Destaca-se que algumas espécies desse gênero são classificadas como ameaçados de extinção, segundo a Lista Oficial das Espécies da Fauna Brasileira, emitida pelo IBAMA, além dos Livros Vermelhos de Fauna Ameaçada nos estados de São Paulo (Bressan et al. 2009) e Paraná (Mikich \& Bérnils 2004).

As alterações no sistema nervoso são achados comuns nas diferentes espécies de vertebrados. A avaliação clínica de pacientes que apresentam suspeitas de doença neurológica requer um conhecimento fundamental de neuroanatomia e neurofisiologia, permitindo o entendimento de como elementos distintos dentro do sistema nervoso sensorial integram, inter-relacionam e interagem para o animal realizar várias funções normais através das vias eferentes somáticas e viscerais (Bagley \& Mayhew 2002).

Em animais selvagens, a determinação de alterações neurológicas é realizada principalmente por meio da inspeção, enfatizando-se a observação de alterações de consciência, comportamento, postura e marcha (Andrade Neto 2006).

A coleta e análise do líquido cefalorraquidiano (LCR) demonstram ser meios viáveis e eficazes de acesso e avaliação do sistema nervoso, no que diz respeito ao diagnóstico e prognóstico de suas enfermidades (Gama et al. 2005). Bailey \& Vernau (1997) citam que esse exame pode fornecer um índice geral de saúde do sistema nervoso central, podendo muitas vezes evidenciar doenças no mesmo, apresentando razoável sensibilidade e baixa especificidade.

Neste sentido, o presente estudo objetivou verificar a segurança e a eficácia da coleta do LCR da cisterna magna de Alouatta guariba, clinicamente sadios, assim como descrever os resultados das análises físico-química e citológica deste fluido.

\section{MATERIAL E MÉTODOS}

O estudo foi realizado em primatas da espécie Alouatta guariba (Geoffroy Saint-Hilaire, 1812), com idades e sexos diferentes. Foram utilizados oito animais do Centro de Medicina e Pesquisa em Animais Silvestres (CEMPAS), da Faculdade de Medicina Veterinária e Zootecnia (FMVZ), da Universidade Estadual Paulista "Júlio de Mesquita Filho" (Unesp), campus Botucatu. A pesquisa foi aprovada pela Câmara de Ética em Uso Animal (CEUA), da mesma instituição, sob no.170/2009, estando em acordo com os princípios éticos na experimentação animal. Como os estudos envolveram animais silvestres da fauna brasileira, também se obteve autorização do Instituto Chico Mendes de Conservação da Biodiversidade (ICMBio), através do Sistema de Autorização e Informação em Biodiversidade (SISBio).

Inicialmente os animais foram submetidos a exames de sanidade, incluindo os seguintes procedimentos: anamnese com tratadores e veterinários responsáveis pelos primatas, exame físico completo que consistiu de inspeção em pele, pelos, cavidade oral, mucosas, auscultação cardíaca e pulmonar, termometria retal, palpação dos membros, cauda e abdome. Também foi realizada a radiografia simples de tórax. Nenhum animal demonstrou alteração digna de nota nesses itens avaliados.

Foram coletadas amostras de sangue venoso pela veia braquial ou safena para realização de hemograma e análise de bioquímica sérica (uréia, creatinina e alanina amino transferase) e nenhuma alteração foi constatada nessas provas. Por fim, os animais foram submetidos ao exame de tuberculinização pela inoculação intra-dérmica palpebral de tuberculina aviária e bovina. Todos os animais apresentaram resultados negativos nesta prova. Ressalta-se que os procedimentos foram realizados sob contenção física e química, com uso de puçá e administração intramuscular de cloridrato de cetamina em solução a 10\%, (dose de 8mg/ $\mathrm{kg}$ ) associado a midazolan (dose de $0,5 \mathrm{mg} / \mathrm{kg}$ ). Com os resultados obtidos na avalição de sanidade, todos os indivíduos foram considerados aptos para a pesquisa.

No dia do procedimento, após restrição alimentar de 12 horas, os animais foram submetidos à contenção física com puçá e, imediatamente, receberam anestesia geral com cloridrato de cetamina $(8 \mathrm{mg} / \mathrm{Kg})$ associada a cloridrato de xilazina $(1 \mathrm{mg} / \mathrm{kg})$ e midazolan $(0,5 \mathrm{mg} / \mathrm{kg})$, pela via intramuscular. Após anestesia, realizou-se a intubação com sonda orotraqueal número 5,5 e foi inserido cateter flexível $20 \mathrm{G}$ na veia braquial. Os animais receberam infusão de solução de cloreto de sódio 0,9\%, para manutenção de acesso venoso e passaram então, a receber anestesia inalatória com isoflurano.

Com o intuito de visualizar a área a ser puncionada, realizou-se a tricotomia ampla da região cervical dorsal. Posteriormente, foi realizada a antissepsia com solução de álcool a 70\% e iodo polivinil pirrolidona. $\mathrm{O}$ animal foi então posicionado com a coluna vertebral paralela à borda da mesa de procedimento e teve sua cabeça flexionada ventralmente, promovendo a abertura do forame magno. 0 operador, munido de luvas de procedimento estéreis e agulha, (Agulha Peridural BD ${ }^{\circledR}$ Tuohy Pediátrica 20G 2") inseriu a mesma no ponto de intersecção entre a linha média e uma linha imaginária unindo a porção cranial das asas do atlas (Fig.1A,B).

Após a progressão lenta com a agulha, retirava-se o mandril e, caso o LCR fosse observado gotejando, o manômetro (Rucken ${ }^{\circledR}$ Instrumentação e Automação Industrial Ltda, São Paulo, SP) era conectado e posicionado no mesmo nível do crânio (Fig.2). Seguida a observação da estabilização do ponteiro, realizava-se a leitura da pressão liquórica inicial. 0 manômetro utilizado para a captação das medidas foi do tipo analógico, com medidas mínima e máxima compreendidas entre zero e $100 \mathrm{~cm}$ de $\mathrm{H} 20$, graduado de uma a uma unidade. Ao término da aferição da pressão inicial, coletava-se a amostra do fluido por gotejamento até que o mesmo cessasse. Nesse momento, o manômetro era novamente conectado ao cateter para nova leitura da pressão. Finalmente, retirava-se o cateter e aplicava-se nova antissepsia no local puncionado.

As amostras de líquido cefalorraquidiano (LCR) coletadas foram analisadas imediatamente quanto aos aspectos físicos (volume, coloração, aspecto e densidade), químicos ( $\mathrm{pH}$, proteína e glicose) e citológicos (hemácias e células nucleadas). Foi realizado também o Teste de Pandy (aplicação de índice colorimétrico para detecção de globulinas com a adição de composto fenólico à amostra de LCR). Para determinação do $\mathrm{pH}$ e glicose utilizou-se fitas reagentes (Combur Test ${ }^{\circledR}$ UX. Roche Diagnostics GmbH, Mannheim, Germany). Para a concentração de proteína liquórica utilizou-se kit Microprote (Microprote Pirogalol Doles ${ }^{\circledR}$. Goiânia, Goiás, Brasil). A densidade das amostras foi realizada com o uso de refratômetro portátil. 0 número total de células nucleadas foi determinado em câmara de Fuchs-Rosenthal. 0 diferencial dos tipos celulares foi obtido mediante citocentrifugação das amostras e coloração das lâminas com corante panótico. A leitura foi realizada em microscópio óptico. 


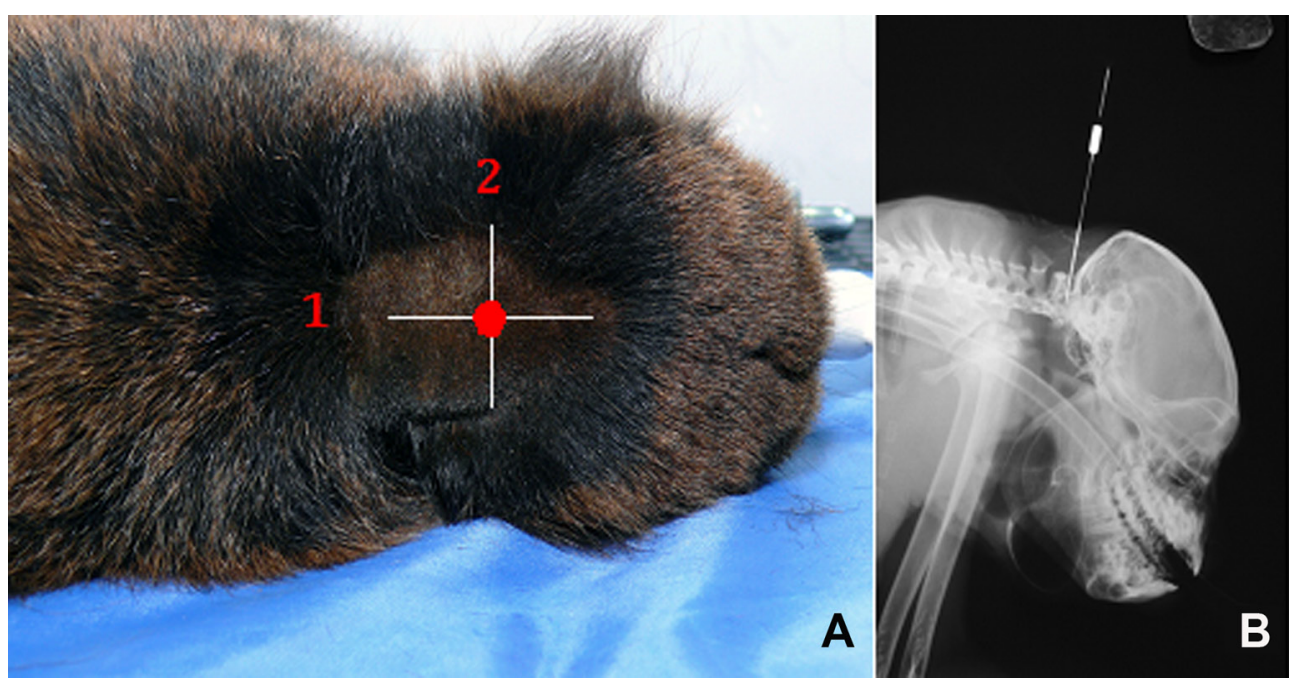

Fig.1. (A) Representação esquemática do ponto de punção da cisterna magna, definido anatomicamente pela intersecção entre a linha média (linha 1) e uma linha imaginária unindo o limite cranial das asas do atlas (linha 2). (B) Radiografia de Alouatta guariba com agulha inserida na cisterna magna.

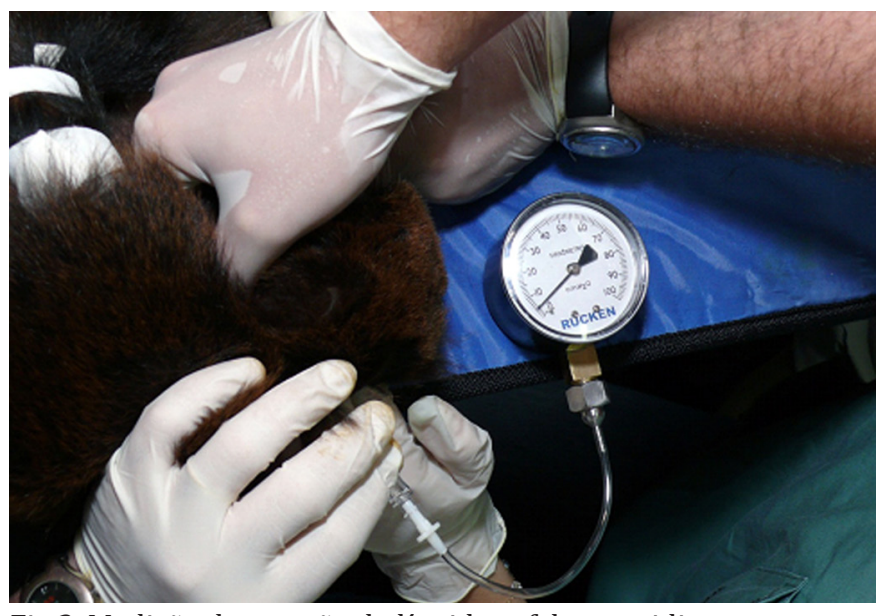

Fig.2. Medição da pressão do líquido cefalorraquidiano com o uso de manômetro analógico.

\section{RESULTADOS}

A metodologia empregada foi adequada e segura para a coleta das amostras de líquido cefalorraquidiano (LCR) na cisterna magna, e nenhum dos animais apresentou complicações durante o procedimento. 0 manuseio do cateter foi simples e o calibre utilizado mostrou-se adequado para a coleta nesses animais. Nos dias posteriores ao procedimento, a inspeção dos animais demonstrou comportamento normal no recinto quanto à ingestão de alimentos, interação com o grupo, movimentação entre os poleiros do recinto, marcha e equilíbrio. Todas as análises realizadas e os valores individuais de cada animal estão representados no Quadro 1.

0 volume de LCR retirado variou entre meio e dois mililitros (média de 1,19mL $\pm 0,53$ ). Os resultados de coloração do líquor demonstraram que as oito amostras apresentaram-se incolores e límpidas. Todas as amostras avaliadas apresentaram densidade de 1,006. Os valores determinados de $\mathrm{pH}$ liquórico mostraram média de 8,37 $\pm 0,69$. 0 teste de Pandy foi realizado em três das oito amostras e todos foram negativos, não se observando alteração na coloração e aspecto das amostras testadas.

Os valores encontrados na análise de glicose liquórica (glicorraquia) apresentaram média de 131,25mg/ $\mathrm{dL} \pm 106,7$. 0 valor médio das proteínas nas amostras foi de $16,92 \mathrm{mg} / \mathrm{dL} \pm 9,84$.

Nas análises citológicas do LCR, observou-se a presença de hemácias e células nucleadas. 0 número médio de hemácias foi de 49,37 hemácias $/ \mathrm{mm}^{3} \pm 111,76$. A média de células nucleadas encontrada nas amostras foi de 0,5 células/ $\mathrm{mm}^{3} \pm 0,75$.

Conforme a metodologia empregada, registrou-se a pressão liquórica antes e após a retirada do LCR. 0 valor médio da pressão inicial foi 7,37 $\mathrm{cm} \mathrm{H}_{2} \mathrm{O} \pm 1,77$ e da pressão final foi $0,62 \mathrm{~cm} \mathrm{H}_{2} \mathrm{O} \pm 1,06$.

\section{DISCUSSÃO}

A coleta do líquido cefalorraquidiano (LCR) pela punção suboccipital demonstrou ser eficiente e segura. Os procedimentos ocorreram sem intercorrências, como hemorragias, e o local escolhido foi apropriado, pois permitiu a inserção da agulha até a cisterna magna para coleta das amostras e medição da pressão liquórica, corroborando os dados de literatura (Reis et al. 1980, Machado 2006, Johanson 2008). A experiência do coletor também foi importante para a coleta da amostra, sendo observada alguma dificuldade nos primeiros procedimentos realizados. Este dado também está de acordo com o relatado por Reis et al. (1980).

Os métodos empregados na análise das amostras do LCR foram os mesmos descritos na literatura consultada (Reis et al. 1980, Bailey \& Vernau 1997, Oliver et al. 1997, Gama et al. 2005, Vernau et al. 2008), sendo que estes, já estão bem definidos e aplicados corriqueiramente na medicina de pacientes humanos e de animais domésticos.

0 volume médio de líquor retirado foi de 1,19 $\pm 0,53 \mathrm{~mL}$. Não foram encontrados valores comparativos na literatura 
Quadro 1. Sexo, idade e variáveis analisadas no líquido cefalorraquidiano, coletado na cisterna magna, de oito bugios-ruivos (Alouatta guariba)

\begin{tabular}{|c|c|c|c|c|c|c|c|c|c|c|}
\hline \multirow[t]{2}{*}{ Característica } & \multicolumn{8}{|c|}{ Animal } & \multirow{2}{*}{\multicolumn{2}{|c|}{ Média e desvio padrão }} \\
\hline & 1 & 2 & 3 & 4 & 5 & 6 & 7 & 8 & & \\
\hline Sexo & M & $\mathrm{F}$ & M & $\mathrm{M}$ & $\mathrm{F}$ & M & $\mathrm{F}$ & $\mathrm{F}$ & & \\
\hline Idade (anos) & 8 & 4 & 2 & 12 & 12 & 8 & 4 & 2 & 6,50 & $\pm 4,66$ \\
\hline Volume (mL) & 0,5 & 1 & 1 & 1 & 2 & 2 & 1 & 1 & 1,19 & $\pm 0,53$ \\
\hline Cor & Incolor & Incolor & Incolor & Incolor & Incolor & Incolor & Incolor & Incolor & NA & NA \\
\hline Aspecto & Límpido & Límpido & Límpido & Límpido & Límpido & Límpido & Límpido & Límpido & NA & NA \\
\hline Densidade & 1,006 & 1,006 & 1,006 & 1,006 & 1,006 & 1,006 & 1,006 & 1,006 & 1,006 & 0 \\
\hline $\mathrm{pH}$ & 9 & 9 & 9 & 8 & 8,5 & 7 & 8,5 & 8 & 8,37 & $\pm 0,69$ \\
\hline Proteína (mg/dL) & 4,0 & 17,7 & 3,2 & 31,8 & 25,8 & 14,1 & 18,7 & 20,1 & 16,92 & $\pm 9,84$ \\
\hline Glicose (mg/dL) & 100 & 50 & 100 & 100 & 300 & 50 & 300 & 50 & 131,25 & $\pm 106,7$ \\
\hline Pandy & NR & NEG & NR & NR & NR & NEG & NEG & NR & NA & NA \\
\hline Hemáceas (cél/mm3) & 0 & 0 & 0 & 67 & 320 & 7 & 1 & 0 & 49,37 & $\pm 111,76$ \\
\hline Células Nucleadas (cél/mm3) & 0 & 0 & 0 & 1 & 1 & 2 & 0 & 0 & 0,5 & 0,75 \\
\hline Pressão Inicial (cm H2O) & 10 & 9 & 9 & 6 & 5 & 7 & 6 & 7 & 7,37 & $\pm 1,77$ \\
\hline Pressão Final (cm H2O) & 0 & 0 & 3 & 1 & 0 & 0 & 0 & 1 & 0,62 & $\pm 1,06$ \\
\hline
\end{tabular}

$\overline{\mathrm{NR}}=$ não realizado, $\mathrm{NEG}=$ negativo, $\mathrm{NA}=$ não se aplica.

consultada. Os resultados de aspecto e coloração demonstraram que não ocorreram contaminações da amostra de LCR com sangue decorrente de acidentes na punção. Os valores determinados de $\mathrm{pH}$ liquórico mostraram média de $8,37 \pm 0,69$. 0 valor da densidade aferida em todas as amostras foi 1,006 , valor este compatível com a faixa de valores de densidade em animais domésticos, de 1,003 a 1,012 conforme citam Feitosa et al. (2005) e Gama et al. (2005).

Os valores de glicose encontrados neste estudo apresentaram média de $131,25 \mathrm{mg} / \mathrm{dL} \pm 106,7 \mathrm{mg} / \mathrm{dL}$, acima dos valores descritos na literatura por Reis et al. (1980). A concentração da glicose no LCR representa $80 \%$ da glicose sérica, e a glicorraquia pode aumentar em algumas situações específicas como traumas, lesões, diabetes melito, dentre outras causas. Na rotina de trabalho com primatas não humanos podemos ressaltar que o estresse pode elevar a glicemia (Almosny 2009), mas não foram encontradas referências que relacionassem estes achados. Como os animais utilizados no estudo vivem permanentemente em cativeiro e não apresentam sinais clínicos que possam sugerir uma doença hiperglicêmica, podemos sugerir que este valor encontrado pode estar relacionado com o estresse e manejo na contenção dos mesmos para coleta das amostras.

Na medição da proteína do líquor, o valor médio encontrados foi de $16,92 \mathrm{mg} / \mathrm{dL} \pm 9,84$. Esta análise para a maioria dos autores consultados é uma das mais importantes no estudo do LCR, pois auxilia no diagnóstico das enfermidades inflamatórias e infecciosas (Reis et al. 1980, Bailey \& Vernau 1997, Feitosa et al. 2005, Gama et al. 2005). Os resultados destas análises encontraram-se dentro da faixa de normalidade para cães (Bailey \& Vernau 1997) e humanos (Reis 1980).

Quanto à celularidade, o número médio de hemácias encontradas nas análises de líquor foi de 49,37 hemácias/ $\mathrm{mm}^{3} \pm 111,76$. Observando individualmente os valores, verifica-se que quatro amostras não apresentaram estas células, e nas que continham possivelmente foi resultante de contaminação com sangue periférico no momento da punção. Este tipo de ocorrência encontra-se descrito na literatura sendo que o LCR normal não apresenta hemácias (Bailey \& Vernau 1997, Gama et al. 2005). A média de célu- las nucleadas encontrada nas amostras foi de 0,5 células/ $\mathrm{mm}^{3} \pm 0,7559$. Analisando-se os dados de forma individual, observamos que em cinco animais não foram observadas células nucleadas e o valor médio encontrado para esta variável está próximo ao citado na literatura para outras espécies (Reis et al. 1980, Bailey \& Vernau 1997, Gama et al. 2005). Pelo pequeno número de células nucleadas encontradas no LCR, apesar do uso de citocentrífuga, não foi possível realizar o diferencial dos tipos celulares considerando-se 100 células. Porém, observou-se ao microscópio óptico um predomínio de células mononucleares.

Os registros de pressão liquórica inicial mostraram valor médio de $7,37 \pm 1,77 \mathrm{~cm} \mathrm{H}_{2} \mathrm{O}$. A pressão final foi $0,62 \mathrm{~cm}$ $\mathrm{H}_{2} \mathrm{O} \pm 1,06$. Os valores iniciais encontrados para medições realizadas na cisterna magna estão dentro dos valores referenciais para humanos, que variam entre cinco e 20 centímetros de água (Reis et al. 1980, Machado 2006, Johanson 2008). Não foram encontrados na literatura valores referenciais em primatas. Mesmo com o risco de aumento da pressão intracraniana pelo uso da cetamina (Vilani 2009), optou-se por este protocolo pela segurança e facilidade de administração (Olberg 2007, Vilani 2009, Chagas et al. 2010, Fasano 2010). Também não foram encontrados valores correspondentes à pressão final, uma vez que com a retirada da amostra, a pressão diminui e a reposição é muito mais lenta que a retirada. Ressalta-se neste resultado que mesmo com a pressão próxima a zero nenhuma alteração foi observada na frequência cardiorrespiratória do paciente. Este dado sugere que a retirada de LCR até o fim do gotejamento espontâneo é uma manobra segura.

\section{CONCLUSÕES}

A coleta do LCR na cisterna magna de bugios-ruivos (Alouatta guariba) é um método seguro e eficaz.

Os resultados obtidos nas análises físico-químicas e citológicas do LCR de macacos em cativeiro, clinicamente sadios, demonstraram valores médios de proteína de $16,92 \mathrm{mg} / \mathrm{dL} \pm 9,84$; glicose de $131,25 \mathrm{mg} / \mathrm{dL} \pm 106,7 ; \mathrm{pH}$ $8,37 \pm 0,69$; células nucleadas $0,5 / \mathrm{mm}^{3} \pm 0,75$ e pressão $7,37 \mathrm{~cm} \mathrm{H}_{2} \mathrm{O} \pm 1,77$. 
Os achados contribuem com a determinação de valores de referência, auxiliando os médicos veterinários de animais selvagens na interpretação das análises do LCR, para o diagnóstico das encefalopatias e mielopatias que acometem esta espécie.

Agradecimentos.- Aos funcionários, professores e residentes do Centro de Medicina de Animais Silvestres (Cempas), FMVZ-Unesp, Botucatu, pela cessão dos animais, dos equipamentos e instalações, e a Daniel Ornelas e Ricardo Coelho Lehmkuhl pelos trabalhos fotográficos.

\section{REFERÊNCIAS}

Andrade Neto J.P. 2006. Neurologia, p.1105-1127. In: Cubas Z.S., Silva J.C.R. \& Catão-Dias J.L. (Eds), Tratado de Animais Selvagens: medicina veterinária. Roca, São Paulo.

Almonsy N.R.P. 2009. Patologia clínica em primatas, p.69-88. In: Kindlovits A. \& Kindlovits L.M. (Eds), Clínica e Terapêutica em Primatas Neotropicais. $2^{\mathrm{a}}$ ed. L.F. Livros, Rio de Janeiro.

Bagley R.S. \& Mayhew I.G. 2002. Exame clínico do sistema nervoso, p. 384420. In: Radostits O.M., Mayhew I.G.J. \& Houston D.M. (Eds), Exame Clínico e Diagnóstico em Veterinária. Guanabara Koogan, Rio de Janeiro.

Bailey C.S. \& Vernau W. 1997. Cerebrospinal fluid, p.785-827. In: Kaneko J.J., Harvey J.W. \& Bruss M.L. (Eds), Clinical Biochemistry of Domestic Animals. Academic Press, San Diego.

Bressan P.M., Kierulff M.C., Sugieda A.M. 2009. Fauna Ameaçada de Extinção no Estado de São Paulo: vertebrados. Fundação Parque Zoológico de São Paulo, Secretaria do Meio Ambiente, São Paulo.

Chagas J.A.B., Oleskoviczi N., Moraes A.N., Flôres F.N., Corrêa A.L., Souza Júnior J.C., Soares A.V. \& Costa A. 2010. Associação de cetamina S(+) e midazolam pelo método convencional de cálculo e pela extrapolação alométrica em bugios-ruivo (Alouatta guariba clamitans): resposta clínica e cardiorrespiratória. Ciência Rural 40 (1):109-114.

Fasano D.M. 2010 Anestesia e controle da dor, p.365-383. In: Andrade A.,
Andrade M.C.R., Marinho A.M. \& Ferreira Filho J. (Eds), Biologia, Manejo e Medicina de Primatas Não Humanos na Pesquisa Biomédica. Editora Fiocruz, Rio de Janeiro.

Feitosa M.M., Ikeda F.A., Bonello F.L., Ciarlini P.C., Gonçalves M.E., Lima V.M.F. \& Perri S.H.V. 2005. Avaliação liquórica de cães, com e sem sintomatologia neurológica, naturalmente acometidos por leishmaniose visceral. Vet. Notícias 11(2):61-69.

Gama F.G., Nishimori C.T., Sobreira M.R. \& Santana A.E. 2005. Caracteres físico-químicos e citológicos do liquor de cães em diferentes fases da cinomose. Ciência Rural 35(3):596-601.

Gregorin R. 2006. Taxonomia e variação geográfica das espécies do gênero Alouatta Lacépède (Primates, Atelidae) no Brasil. Revta Bras. Zool. 23(1):64-144.

Johanson C.E., Ducan III J.A., Klinge P.M., Brinker T., Stopa E.G. \& Silverberg G.D. 2008. Multiplicity of cerebrospinal fluid functions: New challenges in health and disease. Cerebrospinal Fluid Research 5(10), maio. Disponível em <http://www.fluidsbarrierscns.com/content/5/1/10> Acesso em 20 mai. 2012.

Machado A. 2006. Neuroanatomia Funcional. Atheneu, São Paulo. 363p.

Mikich S.B. \& Bérnils R.S. 2004. Livro Vermelho da Fauna Ameaçada no Estado do Paraná. Instituto Ambiental do Paraná, Curitiba.

Olberg R. 2007. Monkeys and Gibbons, p.375-383. In: West G., Heard D. \& Caulkett N. (Eds), Zoo Animal and Wildlife Immobilization and Anesthesia. Blackwell Publishing Professional, Iowa.

Oliver J.E., Lorenz M.D. \& Kornegay J.N. 1997. Handbook of Veterinary Neurology. $3^{\text {rd }}$ ed. W.B. Saunders, Philadelphia, p.89-108.

Reis J.B., Bei A. \& Reis Filho J.B. 1980. Líquido Cefalorraquidiano. Sarvier, São Paulo. 250p.

Vernau W., Vernau K.A. \& Bailey C.S. 2008. Cerebrospinal fluid, p.768-819. In: Kaneko J.J., Harvey J.W. \& Bruss M.L. (Eds), Clinical Biochemistry of Domestic Animals. $6^{\text {th }}$ ed. Elsevier, San Diego.

Vilani R.G.D.C. 2009 Contenção química e anestesia em primatas não-humanos, p.297-310 In: Kindlovits A \& Kindlovits L.M. (Eds), Clínica e Terapêutica em Primatas Neotropicais. $2^{\underline{a}}$ ed. L.F. Livros, Rio de Janeiro. 